\title{
Primary Frequency Regulation using HVDC terminals controlling Voltage Dependent Loads
}

\author{
Marius Langwasser, Student Member, IEEE, Giovanni De Carne, Member, IEEE, Marco Liserre, Fellow, IEEE, \\ and Matthias Biskoping
}

\begin{abstract}
HVDC can provide frequency regulation during disturbances (e.g., faults) by controlling the power flow between two remote $\mathrm{AC}$ areas. While this action reduces the power deviation in the area affected by the disturbance, it causes a power imbalance in the other healthy AC area, leading to a frequency variation and endangering the system stability. In this work, a HVDC primary frequency regulation controlling voltage-dependent loads (PFRVDL) is proposed, where the HVDC terminal in the healthy area influences the grid voltage amplitude to shape (decreasing or increasing) the load consumption in order to cope with the power variation required by the fault-affected area. The PFR-VDL extracts the needed energy for the frequency support, not from the generators (with following frequency deviation) but from the voltage-dependent loads in the healthy area. This work analyzes the PFR-VDL performance, generalizing it with two possible HVDC connection cases: Asynchronous connection with single HVDC line, and embedded HVDC forming a parallel, hybrid connection with HVAC. The PFR-VDL application benefits and limitations are evaluated analytically and verified by means of PSCAD EMTDC simulations, and finally validated with a large interconnected IEEE 39 bus system.
\end{abstract}

Index Terms-HVDC, Load Voltage Sensitivity, Primary Frequency Regulation, Voltage Dependent Loads.

\section{INTRODUCTION}

The energy production share has kept shifting in the last years from conventional generators to power electronicsinterfaced ones, such as wind and solar power plants. These resources provide no rotational inertia contribution to the grid, decreasing the system's damping during power unbalances. As consequence, faster and larger frequency transients occur in the system compared to before, when the energy was produced uniquely from conventional generators. This issue gained attention in the last six month, as two major low frequency incidents in Continental Europe [1] and UK [2] occurred. As practical example in [3], the conventional generators offer an aggregated inertia $H=6 \mathrm{~s}$, which falls down to $3-4 \mathrm{~s}$ during the wind and $\mathrm{PV}$ plant production peaks. Hence, an increased frequency deviation from the nominal value is observed following a specific disturbance (e.g., grid

The authors gratefully acknowledge funding by the German Federal Ministry of Education and Research (BMBF) within the Kopernikus Project ENSURE "New ENergy grid StructURes for the German Energiewende" (03SFK1I0 and 03SFK1I0-2) and by the Ministry of Science, Research and the Arts of the State of Baden-Württemberg Nr.33 - 7533. - 30 - 10/67/1.

Marius Langwasser and Marco Liserre are with the Chair of Power Electronics, Kiel University, Kiel, Germany, e-mail: mlan@tf.uni-kiel.de

Giovanni De Carne is with the Institute for Technical Physics, Karlsruhe Institute of Technology, Karlsruhe, Germany, e-mail: giovanni.carne@kit.edu

Matthias Biskoping is with the ABB Research Center Ladenburg, ABB AG, Ladenburg, Germany, e-mail: matthias.biskoping@de.abb.com faults or large generator/load shut-down), e.g. from $400 \mathrm{mHz}$ to more than $550 \mathrm{mHz}$ [3]. The frequency control is provided by synchronous machines that adapt their power output during disturbances. However, the effectiveness of the control action is constrained by the turbine slow dynamic (tens of seconds range).

The use of Voltage Source Converter (VSC) HVDC systems can increase the system controllability, varying their power output rapidly (within hundreds of ms), following a frequency variation. An existing field application of the primary frequency regulation by HVDC systems is the Caprivi Link Interconnector HVDC Light, connecting weak grids such as the Namibia and Zambia ones [4], [5]. Although this strategy has been largely discussed in literature [6]-[8], it creates power imbalances in the connected areas, leading to frequency variations up to $500 \mathrm{mHz}$ [7]. Industrial documents [4], [5] showed that this represents a huge restriction in frequency regulation depending on the strength of the supporting grid .

Existing control strategies have been applied only in case of asynchronous areas connection. However, modern power system, being limited in building new infrastructure, embeds HVDC systems in AC grids, forming hybrid HVDC-HVAC interconnections [9], [10]. Practical examples are the SuedLink and SuedOstLink projects in Germany [11], both $2 \mathrm{GW}$ underground cable HVDC links. These links are designed to transmit the energy from the wind power plants in the north of Germany toward the southern industrial load centers, to compensate the missing energy from decommissioned nuclear and gas power plants. Both projects are co-operated by two different TSOs, showing that HVDC applications are not only limited to single-operator systems.

To overcome these limitations, primary frequency regulation through voltage-dependent loads (PFR-VDL), e.g. industrial aluminum or steel plants or HV substations [12], approach can be used. The HVDC converter exploits the voltage-power characteristic of the loads, and shapes their consumption by means of controlled voltage variations [13]. This technique has seen several applications with static var compensators [14], synchronous condensers [15], Smart Transformers [16] and load tap changers. The latter, however, seem more suitable for secondary/tertiary frequency control, due to their relatively slow dynamic that is more appropriate for conservation voltage reduction [17].

In this work, the PFR-VDL approach by HVDC-terminals, introduced in the previous literature only for simplified cases [18], is analyzed mathematically by means of state-space analysis and the study cases have been expanded in large 

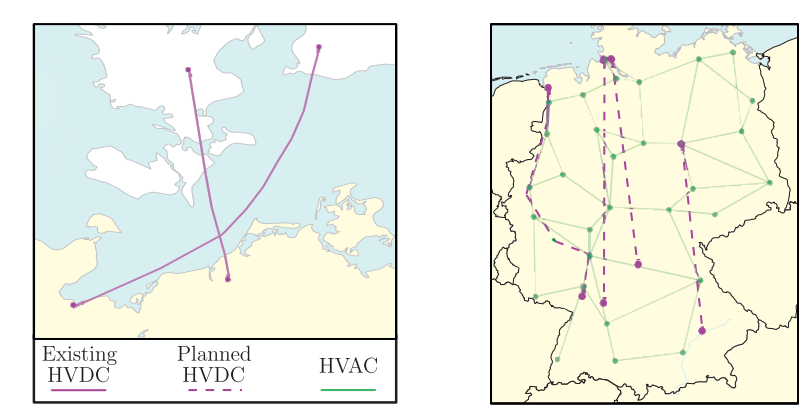

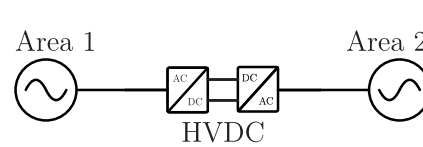

(a)

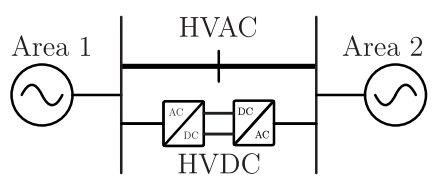

(b)
Fig. 1. Example and schematic of two-area interconnection: (a) Case I: Single HVDC (Germany - Denmark), (b) Case II: Parallel, hybrid HVDC-HVAC (embedded HVDC links in Germany)

and more realistic PSCAD-EMTDC simulations, considering all the possible HVDC connections with the AC grid [11]: asynchronous connection with single HVDC line (e.g., between Germany and Denmark - Fig 1), and embedded HVDC forming a parallel, hybrid connection with existing HVAC grid (in green), such as the planned HVDC corridors in Germany (in pink).

This work is structured as follows: Section II describes the fundamentals of HVDC control and frequency regulation, Section III introduces the PFR-VDL; Section IV verifies the PFR-VDL improvements in frequency regulation provision with analytic analysis in a simplified system, which are confirmed in Section V by means of PSCAD EMTDC simulations. Section VI validates the system performance by implementing the proposed approach in the IEEE 39 bus system. Finally, Section VII is dedicated to the conclusions.

\section{Fundamentals of HVDC-BASED FREQUENCY REGULATION}

The main feature of HVDC systems is to increase the power flow control in AC grids, either to transfer energy between two remote points or to support the $\mathrm{AC}$ system. In two-terminal HVDC system case (Fig.2), one terminal converter (Area 1) controls the DC voltage, adjusting the active power exchange with the AC grid, while the other converter (Area 2) regulates the DC/AC active power flow. HVDC systems usually participate in ac grid voltage $\left(V_{\mathrm{g}}\right)$ regulation by compensating reactive currents (STATCOM functionality) [19]. This reactive power control, implemented with PI-controller, is independent of active power loop in the two terminals within the converter ampacity.

In the state of the art, an external droop controller is applied for the HVDC-based frequency regulation (Fig.2), which adapts the active power set-point to an AC frequency variation, that is extracted from the grid voltage measurements through phase-locked-loop (PLL). Assuming a frequency disturbance $\Delta f_{1}=f_{1}^{*}-f_{1}$ at the HVDC terminal 1 in Area 1 , the measurement signal is transmitted to terminal 2 , where the

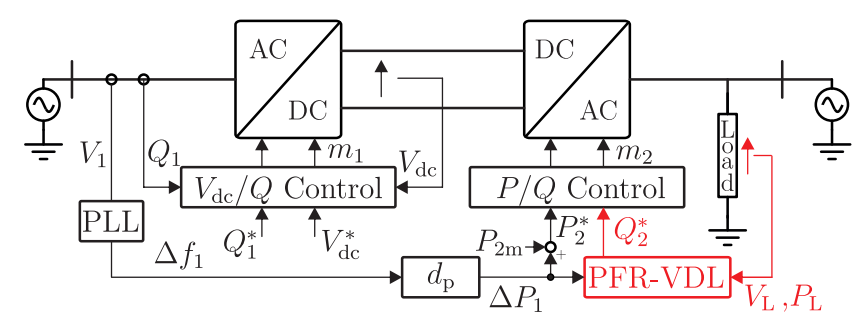

Fig. 2. HVDC control scheme with additional PFR-VDL

active power reference of the HVDC terminal 2 controller is varied following a droop curve $d_{\mathrm{p}}$ (green part in Fig 3), with $P_{2 \mathrm{~m}}$ being the agreed market power set-point:

$$
P_{2}^{*}=P_{2 \mathrm{~m}}+\Delta P_{1}=P_{2 \mathrm{~m}}+d_{\mathrm{p}}\left(f_{1}^{*}-f_{1}\right)
$$

A dead-band is implemented in the PFR to prevent the controller from acting in normal frequency condition, where only small deviations around the frequency nominal value occur. During the control a communication delay has to be considered, which is caused by the distance between the two terminals (e.g. $d=5 \mathrm{~ms}$ ).

In the presented work, the PFR is implemented in the active power controlling terminal (Area 2 HVDC terminal) acting on the frequency in Area 1. However, as demonstrated in [8], the implementation in dc voltage control or in combination with a voltage-droop controller (in the case of a multiterminal HVDC grid) is also feasible. The latter requires special attention to control stability, since the frequency and voltage droop gains act in opposite directions on the active power reference and hence could cause undesired oscillation. The same controller can be implemented also with Area 2 frequency deviation as input [4], [5]. The control principle will remain the same, such that a frequency deviation would cause a linear change of active power reference. However, the sign of the droop constant will be opposite to the PFR acting on Area 1 frequency.

\section{Primary Frequency Regulation Controlling VOLTAGE-DEPENDENT LOADS}

\section{A. Load Modeling}

Load modeling - the mathematical representation of the load power to voltage dependency - is a critical task for dynamic power system analysis. As result of the TSO/DSO survey in [20], in Europe, the load active power is modeled in $43 \%$ of the cases with a static constant impedance, current or power behavior. $21 \%$ of the loads are modeled with a combination of the three polynomials (called ZIP-model), $10 \%$ use static exponential load modeling, $16 \%$ ZIP plus induction machine and $8 \%$ detailed composite model. However, based on Taylor expansion, polynomial ZIP-models (including the constant impedance, current and power models) can be expressed by their equivalent exponential parameters following the relation given in [20]:

$$
k_{\mathrm{p}}=\frac{p_{P} * 0+p_{I} * 1+p_{Z} * 2}{p_{P}+p_{I}+p_{Z}}
$$


TABLE I

REAL GRID LOAD SENSITIVITIES $K_{\mathrm{p}}$

\begin{tabular}{ccc}
\hline Load type & Equivalent $K_{\mathrm{p}}$ & Reference \\
\hline Commercial (summer/winter) & $0.5 / 0.8$ & {$[12]$} \\
Residential (summer/winter) & $0.9 / 1.7$ & {$[12]$} \\
America HV average & $1.0-1.5$ & {$[20]$} \\
HV aggregated load & 1.3 & {$[14]$} \\
MV aggregated load & 1.35 & {$[21]$} \\
Primary substations & 1.5 & {$[22]$} \\
Industrial aluminum plants & 1.8 & {$[12]$} \\
\hline
\end{tabular}

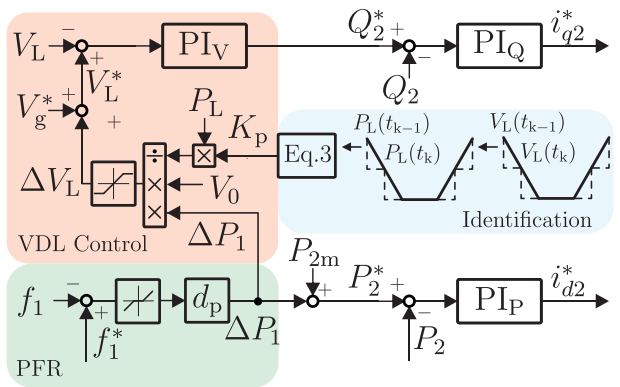

Fig. 3. HVDC PFR-VDL control loops

where $p_{P}, p_{I}$ and $p_{Z}$ are the constant power, constant current and constant impedance components of the total aggregated load. Hence, static exponential load modeling, can express more than $70 \%$ of all used dynamic load models and is best suited as unified model to represent aggregate loads [12].

\section{B. Load voltage sensitivity}

The load power to voltage sensitivity generally depends on the loading conditions, such as weather, season or daytime [12], [21], and the composition of the aggregated load. Several studies (industry surveys and measurements) have been conducted to identify the sensitivity of power systems loads, which represent the aggregation of hundreds or thousands of individual devices connected to the same substation (see Table 【). This work considers active power to voltage sensitivity $K_{\mathrm{p}}=1.8$, in line with the results of [12], where the highest share of load participating in frequency services (59\%) are industrial aluminum plants with average load sensitivity $K_{\mathrm{p}}=1.8$. Lower load sensitivity values do not impede the general PFR-VDL positive effects, but it only reduces its operational margin, since the same active power contribution requires larger voltage variations. Although, a constraint on the grid voltage variations (e.g. \pm 0.02 p.u.) will reduce the PFR-VDL influence on frequency nadir, a positive damping effect is always obtained, which is analyzed in Section IV.B

\section{Load Identification and Control}

Conventional methods to identify the load power to voltage sensitivity make use of two approaches, both based on offline data processing: measurement-based and componentbased approach. In the measurement-based approach, direct measurements of field data at representative substations and feeders are carried out for specific grid disturbances and the obtained data is fitted to the actual load models afterward.
In the component-based approach, individual components in laboratory are aggregated in (sub-)classes of models, which take into account different loading conditions [21]. The aggregation is performed with weighted averaging or curve fitting techniques. These methods, although suitable for identifying loads in steady-state or dynamic studies, lack in capability to provide real time information on the loads status, which is vital for proper corrective action in grid disturbance situation.

The control of flexible, voltage-dependent loads has been considered a valid alternative to classical approaches for balancing the load demand and power generation. In this way, an additional power reserve to be used anytime can be raised, reducing the need for energy storage systems and limiting the degradation effects on synchronous generators. Shaping the loads power consumption through controlled voltage variations can be considered for economic dispatch, primary frequency regulation and contingency reserves [23].

\section{PFR-VDL Algorithm Implementation}

The HVDC PFR-VDL, as proposed in this paper, makes use of the load active power sensitivity to voltage identification [24] (blue part in Fig 3). This approach applies a controlled disturbance in the grid (in this case a controlled reactive power injection that influences the load voltage amplitude $V_{L}$ ), in order to measure the active power variation at the load bus. Following this methodology, the load power sensitivity to voltage $K_{p}$ can be evaluated in real-time every time it is needed or at regular intervals (e.g. every few minutes, see Fig. (4):

$$
K_{p}=\frac{\frac{P_{\mathrm{L}}\left(t_{k}\right)-P_{\mathrm{L}}\left(t_{k-1}\right)}{P_{\mathrm{L}}\left(t_{k-1}\right)}}{\frac{V_{\mathrm{L}}\left(t_{k}\right)-V_{\mathrm{L}}\left(t_{k-1}\right)}{V_{\mathrm{L}}\left(t_{k-1}\right)}}
$$

where $P_{\mathrm{L}}\left(t_{k}\right), P_{\mathrm{L}}\left(t_{k-1}\right), V_{\mathrm{L}}\left(t_{k}\right)$, and $V_{\mathrm{L}}\left(t_{k-1}\right)$ are the active power and voltage measurement at a certain time step $t_{k}$ and its previous one $t_{k-1}$. In this way, the knowledge of the sensitivity is actual within the chosen time resolution. Considering that this analysis has been carried out in high voltage grids, it is expected that the load sensitivity does not vary substantially within minutes. As demonstrated in [25], in MV grids the load sensitivity varies in tens of minutes or hours. Hence, in HV grids a slower variation is expected. The measurement, during the voltage and power variation, is performed locally in the interested HV substation (i.e., the load under control), where the load sensitivity is evaluated, and the value sent to the HVDC controller with a specific time stamp. With this approach, a fast communication is not needed, but the classical communication infrastructure can be employed. Once this sensitivity is known, the load active power consumption can be influenced varying the Area 2 voltage in pu by $\Delta V_{\mathrm{L}} / V_{0}$ as in (4)

$$
\frac{\Delta V_{\mathrm{L}}}{V_{0}}=\frac{\Delta P_{1}}{P_{\mathrm{L}} K_{p}}=\frac{d_{\mathrm{p}} \cdot \Delta f_{1}}{P_{\mathrm{L}} K_{p}}
$$

where $\Delta P_{1}$ represents the power variation requested by the droop controller $d_{\mathrm{p}}$ in Area $1, P_{\mathrm{L}}$ is the load power consumption and $\Delta f_{1}$ is the frequency error in Area 1 (red part in Fig 37. The load voltage change $\Delta V_{\mathrm{L}}$ and, thus, the variation 


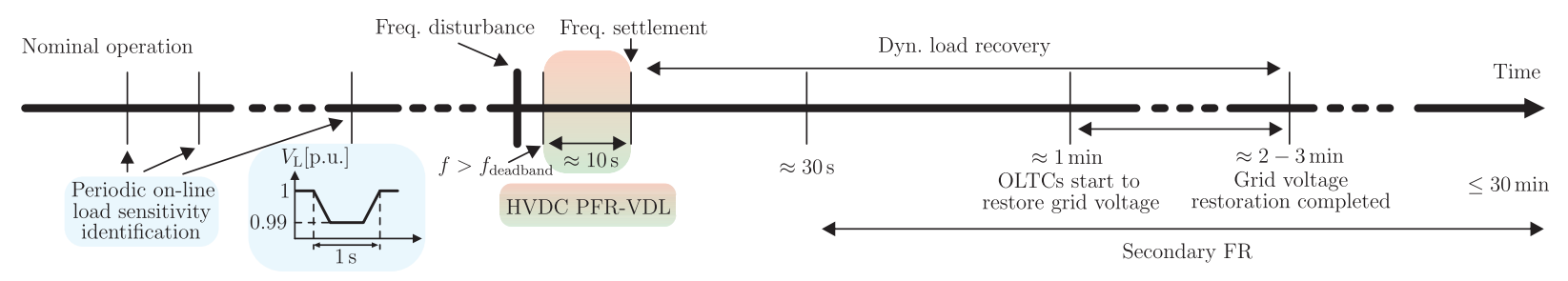

Fig. 4. Timeline of HVDC PFR-VDL application in frequency disturbance case

of its power consumption, are performed through controlled reactive power injection $Q_{2}^{*}$ by the HVDC terminal 2 as shown in Fig.2.

$$
Q_{2}^{*}=(\underbrace{V_{\mathrm{g}}^{*}+\Delta V_{\mathrm{L}}}_{V_{\mathrm{L}}^{*}}-V_{\mathrm{L}})\left(k_{\mathrm{p}, \mathrm{V}}+k_{\mathrm{i}, \mathrm{V}} \frac{1}{s}\right)
$$

where $V_{\mathrm{L}}$ and $V_{\mathrm{L}}^{*}$ represent the load voltage actual and reference value, respectively.

To cope with the power quality challenge, the control algorithm is constrained by the following measures: (1) A dead-band (e.g. $100 \mathrm{mHz}$ ) is implemented in the PFR droop curve to avoid unnecessary control actions for small deviations around the frequency nominal value. (2) The PFR-VDL grid voltage variation is implemented as additional reference value only in abnormal frequency condition and respects grid voltage variation limits of current ENTSO-E network codes for secure grid operation $(0.9-1.118 \mathrm{pu})$ [26] or the stricter constraints of maximum voltage step-change due to reactive power injection in the technical requirements for grid connection of high voltage direct current systems (i.e. \pm 0.02 p.u. [27]). (3) The HVDC active $P_{2}^{*}$ and reactive power set-points $Q_{2}^{*}$ are limited by the maximum HVDC converter ampacity.

Additionally, the feature of load sensitivity identification allows to know beforehand the requested voltage variation at load point and permits to check in advance the compliance with the grid voltage constraints. The control of voltage dependent loads is only applied as corrective action in short time after the disturbance to support the generators primary frequency control. After frequency resettlement, the grid voltage and HVDC reactive power reference are restored to their pre-fault nominal values.

\section{E. Load Recovery}

After the disturbance and control action of PFR-VDL, certain loads will slowly recover and OLTCs will restore the voltage. Typically, they will begin moving one minute after a drop in voltage occurred and complete the restoration of voltage within another one or two minutes [12]. Measurements in medium voltage distribution network in Serbia have confirmed a load recovery time constant around $T_{\mathrm{p}}=398.1 \mathrm{~s}$ for voltage step up and $T_{\mathrm{p}}=221.5 \mathrm{~s}$ for voltage step down [21].

Since the PFR-VDL control action is limited approximately to the first ten seconds after the disturbance, it can be concluded that the load recovery effect can be neglected in this study and the use of static exponential modeling is justifiable.

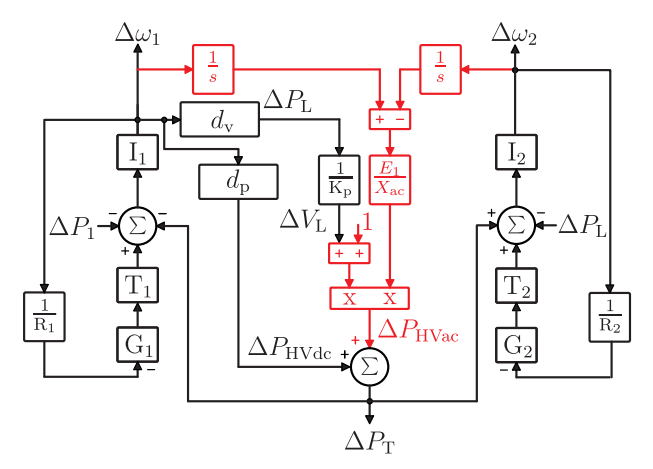

Fig. 5. Two-area system scheme with single HVDC interconnection (black), and parallel hybrid HVDC-HVAC interconnection (red) and PFR-VDL.

TABLE II

PARAMETERS OF TWO-AREA GRID

\begin{tabular}{cccccr}
\hline$R$ & $T_{\mathrm{G}}$ & $F_{\mathrm{HP}}$ & $T_{\mathrm{RH}}$ & $T_{\mathrm{CH}}$ & $F_{\mathrm{LP}}$ \\
\hline 0.05 & $0.2 \mathrm{~s}$ & 0.3 & $7 \mathrm{~s}$ & $0.3 \mathrm{~s}$ & 0.7 \\
\hline$M$ & $D$ & $K_{\mathrm{p}}$ & $E_{1}$ & $X_{\mathrm{ac}}$ & \\
\hline $13 \mathrm{~s}$ & 1 & 1.8 & 1 & 0.022 & \\
\hline
\end{tabular}

\section{Analytical Results}

For an analytical evaluation of the HVDC PFR-VDL performance, the simplified two area system scheme [28] has been used, as shown in Fig 5. This model accurately represents the system with the minimum required level of details for frequency control studies [29]. The system scheme consist of the equivalent machines of the two areas and it is built to adapt the two two-area connection cases under investigation: by means of a HVDC line (black), or embedded HVDCHVAC lines (red) interconnecting the two areas instead of 2 HVAC lines. The HVDC power control is assumed ideal in this case, which results in simplified representation of the HVDC system only respecting its linear frequency power droop gain $d_{\mathrm{p}}$. The internal dynamics of the control of voltage dependent loads are not within the bandwidth of frequency control studies [29]. Hence, a linear relationship between frequency and load voltage can be assumed, which is added by the control gain of voltage dependent loads (VDL) $d_{\mathrm{v}}$ and load voltage sensitivity $K_{\mathrm{p}}$ additionally in this scheme. The two areas system parameters are listed in Table III where $R$ is the governor frequency/power droop, $T_{\mathrm{G}}$ the time constant of first order representation of governor dynamics, $T_{\mathrm{RH}}, F_{\mathrm{HP}}$, $F_{\mathrm{LP}}$ and $T_{\mathrm{CH}}$ the reheater time constant, power fraction of high and low pressure section and time constant of the main 


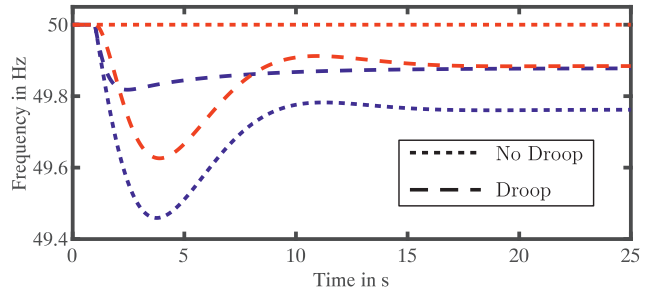

Fig. 6. Case I: Analytical calculation of frequency variation in Area 1 (blue) and Area 2 (red) w/ ('Droop') and w/o ('No Droop') HVDC frequency regulation for $10 \%$ active power load step in Area 1

inlet volume of the turbine, respectively. $M$ represents the equivalent system inertia, $D$ the load damping factor, $E_{1}$ the grid voltage amplitude in area 1 and $X_{\mathrm{ac}}$ the impedance of $\mathrm{AC}$ transmission line between the two areas.

The transfer function of each $x$-area system is given by

$$
\begin{aligned}
I_{\mathrm{x}} & =\frac{1}{M_{\mathrm{x}} s+D_{\mathrm{x}}} \\
G_{\mathrm{x}} & =\frac{1}{1+s T_{\mathrm{G}, \mathrm{x}}} \\
T_{\mathrm{x}} & =\frac{1+s F_{\mathrm{HP}, \mathrm{x}} T_{\mathrm{RH}, \mathrm{x}}}{\left(1+s T_{\mathrm{CH}, \mathrm{x}}\right)\left(1+s T_{\mathrm{RH}, \mathrm{x}}\right)}
\end{aligned}
$$

where $I_{\mathrm{x}}$ represents the rotor inertia and load damping, $G_{\mathrm{x}}$ the governor and $T_{\mathrm{x}}$ the turbine. To analyze the system frequency response under different connection and control solutions, a state-space model (SSM) of the system in Fig 5 has been developed and shown in (11). The dynamic state vector and the output vector are composed respectively of:

$$
\begin{aligned}
& x=\left[\begin{array}{llllllllll}
g 1 & g 2 & i_{1} & i_{2} & \Theta_{1} & \Theta_{2} & \frac{d \tau_{1}}{d t} & \tau_{1} & \frac{d \tau_{2}}{d t} & \tau_{2}
\end{array}\right]^{T} \\
& y=\left[\begin{array}{ll}
\Delta \omega_{1} & \Delta \omega_{2}
\end{array}\right]^{T}
\end{aligned}
$$

with $g_{x}, i_{x}$ and $\tau_{x}$ being the internal states of the governor, rotor inertia and turbine, $\Theta_{x}$ the rotational angle and $\Delta \omega_{x}$ is the frequency variation of the respective area $x$.

\section{A. Investigation of HVDC PFR-VDL performance}

The frequency and power response of the two areas in the aforementioned two cases are described in the following.

Case I: Asynchronous connection with single HVDC interconnection (depicted in black in (11)). An active power load step $\Delta P_{1}=10 \%$ is applied after $1 \mathrm{~s}$ in Area 1 . Two control actions of the HVDC system are considered in Fig 6 : the HVDC system works at constant power and keeps the power exchange with the AC system constant during the disturbance (marked with No Droop), or the HVDC system varies its power request following the frequency-power-droop characteristic (marked with Droop). As can be seen from Fig 6 , the HVDC system at constant power does not support the frequency in Area 1, leading to a large frequency drop below $49.5 \mathrm{~Hz}$. On the contrary, Area 2 is unaffected in this control mode. Instead, the HVDC system with a frequency-powerdroop curve $\left(d_{\mathrm{p}}=20\right)$ modifies its power demand proportionally with the frequency variation in Area 1, which limits the negative frequency peak to $49.8 \mathrm{~Hz}$. However, Fig 6 illustrates the drawback of droop control action: Area 2 experiences
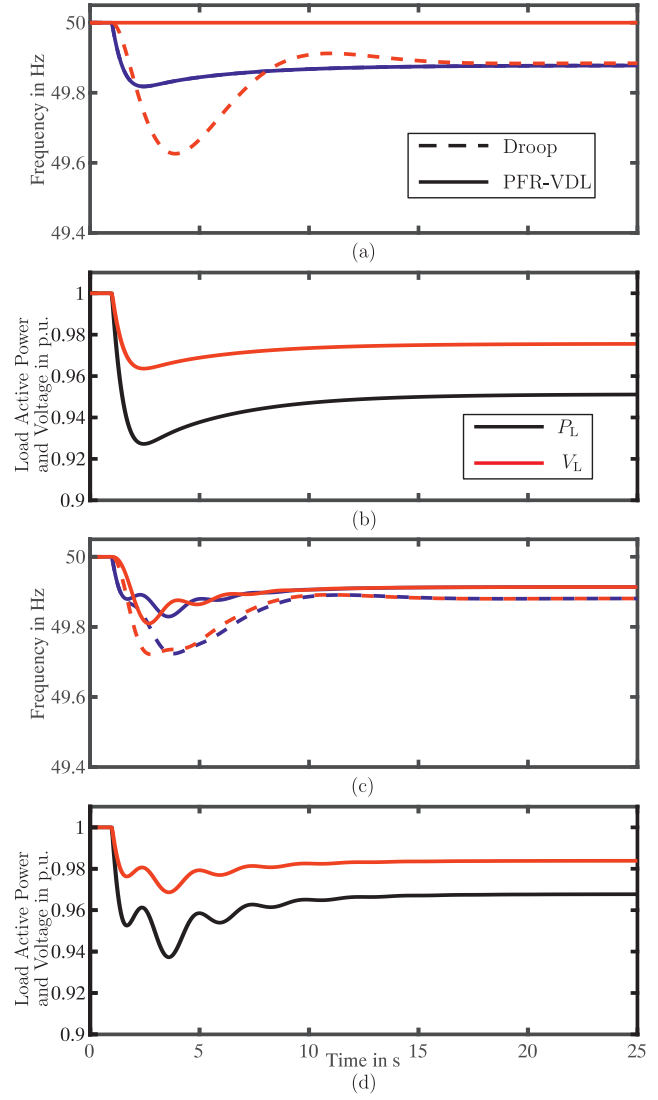

Fig. 7. Analytical calculation of frequency variation in Area 1 (blue) and Area 2 (red) with droop frequency regulation and with HVDC PFR-VDL: (a) Case I, (c) Case II and Analytical calculation of load active power and voltage variation: (b) Case I, (d) Case II for 10\% active power load step in Area 1

a temporary power imbalance and frequency variation up to $49.6 \mathrm{~Hz}$ due to the frequency support in Area 1.

To solve the above mentioned problem, the HVDC PFRVDL is additionally implemented as described in Section IIId. Through voltage variation at the load point of coupling with the power system, an active power variation of the load consumption can partially balance the power variation request from each HVDC terminal (share defined by the parameter $d_{\mathrm{V}}$ ). If the same amount of active power transferred in Area 1 is extracted from the load, the HVDC terminal power can be completely balanced. From Fig 7 a) it can be seen, that the frequency in Area 2 remains unchanged during the whole transient window. Extracting the energy demanded by the HVDC system not only from the local generators but also from nearby voltage-dependent loads, raises additional operational reserve and makes the frequency regulation independent from the network inertia. Estimating the load active power to voltage sensitivity $K_{\mathrm{p}}$ and changing the load voltage accordingly, as in Fig 7(b), guarantees a correct variation of load power consumption (see Fig 7 b)). The load voltage drops by only $4 \%$, which gives high operational margin of PFR-VDL application.

Case II: Embedded HVDC forming a hybrid parallel HVDC-HVAC interconnection (additional equations depicted in red in (11). This solution goes in line with the need for grid controllability enhancement with limited Right of Way 


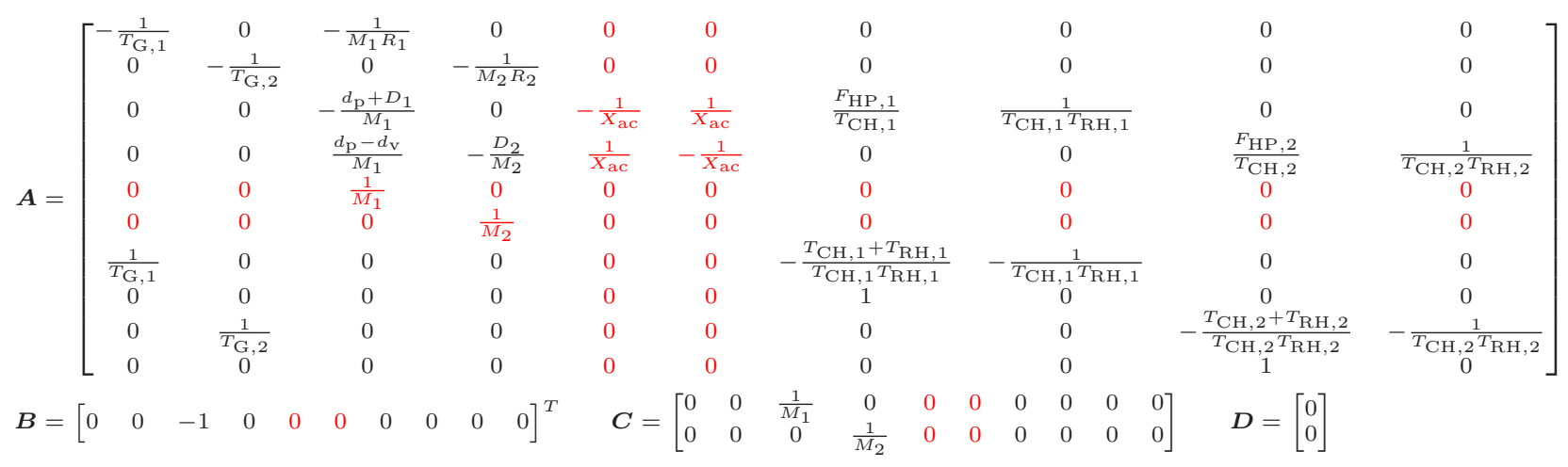

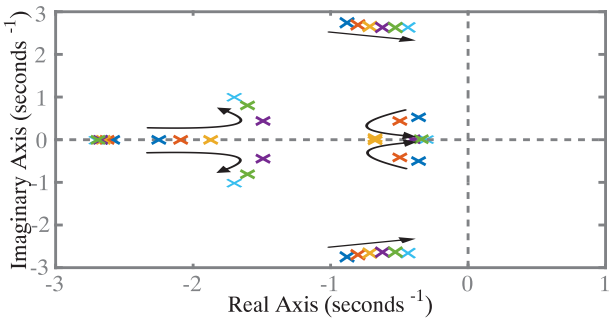

Fig. 8. Case II: Pole-Map of the closed-loop transfer function from active power load step $\Delta P_{1}$ to Area 1 frequency variation $\Delta \omega_{1}$ with increasing VDL control gain $d_{\mathrm{v}}=\left[0 \% d_{\mathrm{p}} \ldots 100 \% d_{\mathrm{p}}\right]$

for new infrastructure. The PFR-VDL impact in Area 2 can be seen in Fig.7 ( c) and Fig.7( (d). The frequency oscillation in both areas is kept above $180 \mathrm{mHz}$ under the PFR-VDL action, while in Droop mode it is falling to $280 \mathrm{mHz}$. However, in contrast to asynchronous HVDC, not only the HVDC power affects the frequency in both areas, but the overall HVDC and HVAC contribution to the transmitted power and the frequency coupling effect through $E_{1} / X_{\mathrm{ac}}$ have to be considered.

Fig. 8 shows the trajectory of the poles of the transfer function from active power load step $\Delta P_{1}$ to frequency variation $\Delta \omega_{1}$, considering an increasing share of VDL control action $d_{\mathrm{v}}$ in Area 2. A high $d_{\mathrm{v}}$ creates 3 effects: 1) a pole movement toward the imaginary axis, corresponding to a marginally reduced system stability, 2) a pole movement away from the real axis, indicating a reduction in system damping at higher frequencies (around $0.5 \mathrm{~Hz}$ ), and 3 ) a pole movement toward the real axis, with an increase of the damping at lower frequencies (around $0.1 \mathrm{~Hz}$ ). This results effectively in a reduced frequency nadir in both areas.

\section{B. Discussion on the load sensitivity}

Changing the load's power consumption by PFR-VDL adds virtual damping to the system. Hence, the maximum frequency deviation in Area 2 varies linearly with the sensitivity $K_{\mathrm{p}}$. In Fig.9(a), three different inertia cases have been considered: $H=6.5 \mathrm{~s}$ of conventional generators in Kundur benchmark; $H=5 \mathrm{~s}$ with mixed generation (as reported in [30]) for North American and European HV transmission network benchmark; and $H=3 \mathrm{~s}$ during wind and PV plant production peaks [3]. If the grid voltage is tightly constrained (e.g. \pm 0.02 p.u. as
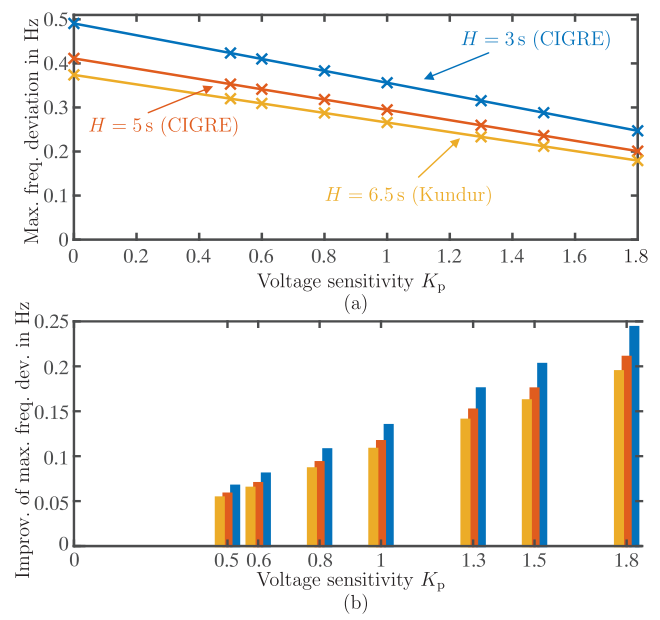

Fig. 9. Case I: Analytical calculation of (a) Maximum frequency deviation in Area 2 with PFR-VDL and (b) Improvement of PFR-VDL compared to Droop control with varying load voltage sensitivity and grid inertia for $10 \%$ active power load step in Area 1 and \pm 0.02 p.u. voltage constraint

requested by the current technical requirements for grid connection of high voltage direct current systems), the efficiency of the PFR-VDL in suppressing the undesired frequency deviation in supporting area 2 is limited. Primary aluminum plants, which show highest sensitivity of $K_{\mathrm{p}}=1.8$, can damp the frequency oscillation by $180 \mathrm{mHz}$ (high inertia) to $250 \mathrm{mHz}$ (low inertia). However, even for very low-sensitive loads (commercial loads in summer, $K_{\mathrm{p}}=0.5$ ) an improvement of up to $50 \mathrm{mHz}$ is obtained compared to the conventional droop control (see Fig.9(b)).

\section{Simulations Results: Simplified test System - ASYNCHRONOUS HVDC}

\section{A. Validation in Kundur two-area four-machine system}

The validation of PFR-VDL improvements in HVDC frequency support is carried out with EMTDC simulations in PSCAD. Allowing simplified result replication, the two-area grid established in [28] has been implemented in PSCAD, replacing the 2 original HVAC lines by an HVDC line (Case I) interconnecting the two areas. The adopted system is represented in Fig. 10 and its parameters are listed in Table III] The HVDC nominal parameters are given in Table IV In this simulation, the loads are modeled as exponential loads [28]. 


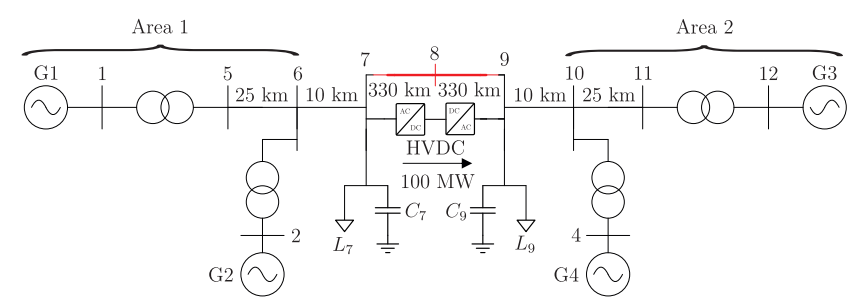

Fig. 10. Two-area four-generator system with single HVDC (black) and parallel, hybrid HVDC/HVAC (red) interconnection

TABLE III

INITIAL SET-POINTS OF GENERATING UNITS AND LOADS OF THE TWO-AREA GRID

\begin{tabular}{cccc}
\hline G1: & $P_{1}=530 \mathrm{MW}$ & $Q_{1}=185 \mathrm{MVar}$ & $E_{\mathrm{t} 1}=1.03 \angle 20.2^{\circ}$ \\
G2: & $P_{2}=530 \mathrm{MW}$ & $Q_{2}=235 \mathrm{MVar}$ & $E_{\mathrm{t} 2}=1.01 \angle 10.5^{\circ}$ \\
$\mathrm{G} 3:$ & $P_{3}=550 \mathrm{MW}$ & $Q_{3}=176 \mathrm{MVar}$ & $E_{\mathrm{t} 3}=1.03 \angle-6.8^{\circ}$ \\
$\mathrm{G} 4:$ & $P_{4}=560 \mathrm{MW}$ & $Q_{4}=202 \mathrm{MVar}$ & $E_{\mathrm{t} 4}=1.01 \angle 17.0^{\circ}$ \\
\hline Bus 7: & $P_{\mathrm{L} 7}=967 \mathrm{MW}$ & $Q_{\mathrm{L} 7}=100 \mathrm{MVar}$ & $Q_{\mathrm{C} 7}=200 \mathrm{MVar}$ \\
Bus 9: & $P_{\mathrm{L} 9}=1,167 \mathrm{MW}$ & $Q_{\mathrm{L} 9}=100 \mathrm{MVar}$ & $Q_{\mathrm{C} 9}=350 \mathrm{MVar}$ \\
\hline
\end{tabular}

TABLE IV

PARAMETERS OF HVDC SYSTEM

\begin{tabular}{cccccc}
\hline Length & $V_{\text {dc,nom }}$ & $V_{\text {ac,nom }}$ & $S_{\text {nom }}$ & $P_{\text {kundur }}$ & $P_{39 \mathrm{bus}}$ \\
\hline $660 \mathrm{~km}$ & $400 \mathrm{kV}$ & $220 \mathrm{kV}$ & $500 \mathrm{MVA}$ & $100 \mathrm{MW}$ & $270 \mathrm{MW}$ \\
\hline
\end{tabular}

The AC grid consists of cables, which are represented with single PI-equivalent, and machines, which include mechanicalhydraulic governor, steam turbine, synchronous generator and Ac2A-type exciter. As a common modeling approach for grid control studies, the HVDC system is represented with its average model. The transient switching behavior of the converters is averaged within one switching interval, such that the AC-DC converter is modeled as a controlled voltage source with series AC filter on the AC side. The source reference input is defined by the modulation waveform calculated by the HVDC controller. The DC side is modeled as controlled current source (to represent the power flow from AC to DC) with parallel DC capacitor. The dc-line is modeled with PIequivalent, with shunt capacitors being included in the DC capacitors of the converter representation.

To validate the PFR-VDL performance in HVDC systems, the application of a $300 \mathrm{MW} / 90 \mathrm{MVAr}$ load step (corresponding around $8 \%$ of the system rating, equal to $3600 \mathrm{MVA}$ ) at $t=15 \mathrm{~s}$ has been supposed in Area 1. The HVDC system can react on the grid perturbation with two possible control actions: keeping the power constant during the disturbance (indicated with 'No Droop' in Fig.111; or adapting its power output to the frequency/power droop characteristic, depicted in Fig.2] and marked in Fig.11 with 'Droop'.

As depicted in Fig.11, no regulation can be provided with HVDC working with constant power, and the frequency in Area 1 experiences a deviation up to $49.2 \mathrm{~Hz}$. The negative frequency peak is limited to $49.6 \mathrm{~Hz}$, if the HVDC system modifies its power output accordingly to the frequency deviation. A temporary power imbalance and frequency variation up to $49.7 \mathrm{~Hz}$ occurs in Area 2, forcing generators to ramp up

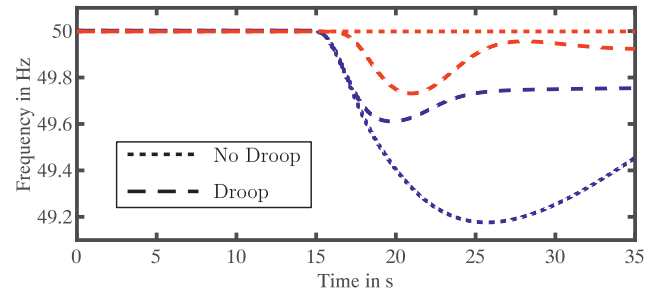

Fig. 11. Case I: Simplified test system: System frequency in Area 1 (blue) and Area 2 (red) w/ (Droop) and w/o (no Droop) HVDC frequency regulation

the power to stabilize the system frequency.

To decrease the impact of the HVDC frequency regulation on Area 2, the PFR-VDL is integrated in Area 2 HVDC terminal, as shown in Fig.2 The PFR-VDL first identifies the load active power sensitivity to voltage, using the methodology derived in [24] and recalled in Section III. The load voltage and thus its active power consumption are modified by HVDC controlled reactive power injection (shown in Fig 12)(b), as can been noticed at $t=5 \mathrm{~s}$ in Fig.12 (c). The voltage, being the grid mainly inductive, is sensitive to reactive power, which allows for PFR-VDL control also with limited ampacity of the VSC. The load voltage and active power measurement data are sampled in the same place (e.g. at HV substation) and synchronized, which implies no communication delay. After the sensitivity estimation, the HVDC applies the PFR-VDL action, if the measured frequency deviation exceeds the deadband of $100 \mathrm{mHz}$. The load voltage varies to match the change in load power consumption with the active power required by the HVDC to limit the frequency deviation in Area 1.

Fig.12 a) shows the effect of the PFR-VDL action. While the Area 1 frequency behaves similar in both cases, the PFR-VDL application reduces the frequency oscillation in Area 2 and hence supports the generators' primary frequency control. From generators active power plots in case of HVDC frequency regulation with and without load participation in Fig.12 (d), it is visible that the PFR-VDL helps the generators $G 3$ and $G 4$ to balance the energy deficit in Area 2. This results in lower increase of their power outputs, both in steadystate and transient conditions. Although the improvements in steady-state are marginal compared to pre-disturbance conditions, the transient power overshoot (i.e., $3 \%$ ) can be avoided and a smoother governor control action can be applied.

\section{B. Discussion on the load participation}

To demonstrate the PFR-VDL performance depending on the electrical distance of the load from the PFR-VDL control point, transmission lines of $0 \mathrm{~km}, 25 \mathrm{~km}$ and $50 \mathrm{~km}$ between the HVDC terminal and the load are introduced in the simulation setup shown in Section IV. To fairly match the system's steady-state condition under different transmission lines, the capacitor value at bus 9 of the Kundur grid and the generators' active power set-points have been adapted to maintain same steady-state voltage and frequency conditions at the load for all cases. As can been seen from Fig.13, the HVDC active power and the frequency in Area 1 are unaffected in all cases. Two effects are visible, if the line length changes: long length 

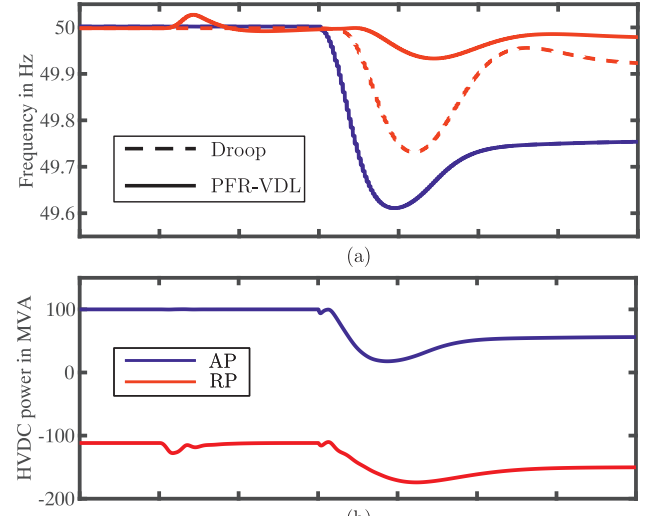

(b)
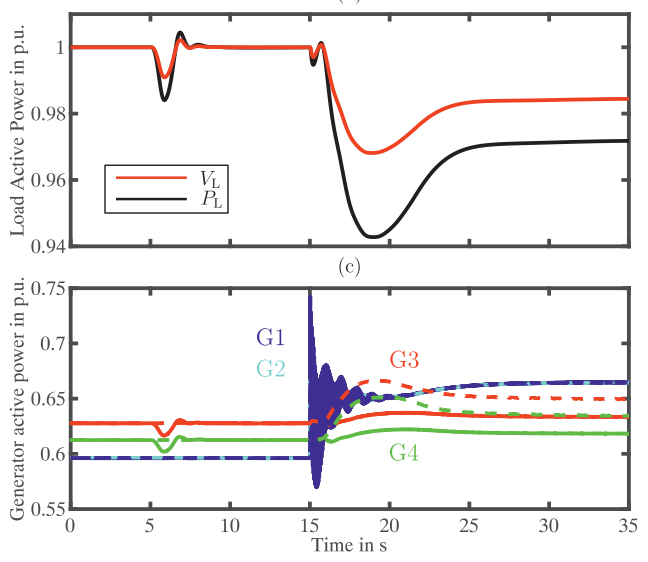

(d)

Fig. 12. Simplified test system: (a) Frequency in Area 1 (blue) and Area 2 (red), (b) HVDC active/reactive power, (c) Load active power and voltage, (d) Generator active power with droop frequency regulation and with PFR-VDL

of transmission line leads to a small increase in reactive power needed for changing the load voltage, due to the voltage drop across the line; and the frequency in Area 2 damping improves with longer lines. This can be explained due to higher losses in longer lines that decrease for a reduced load consumption. For this reason, the total generators' active power is reduced compared to the case with no transmission line.

\section{Simulations Results: LaRge interconnected SYSTEM - IEEE 39 BUS SYSTEM}

\section{A. Validation of HVDC PFR-VDL in interconnected system}

To validate the results in a larger interconnected system, this section shows the simulation results of PFR-VDL control in a modified IEEE 39-bus network [31] (depicted in Fig 14). A HVDC system replaces the AC line between bus 27 (terminal 1) and bus 26 (terminal 2) with identical active power flow of $-270.4 \mathrm{MW}$. The transmission lines are modeled using the Bergeron model, while for HVDC system and generators the same type of modeling as in the Kundur benchmark simulations is used.

To analyze the system performance under a disturbance, at $t=35 \mathrm{~s}$, the bus 39 is disconnected from the main system, including the generator $G_{1}$, the connected load and the lines $1-39$ and $9-39$. Two different study cases have been considered: a case with nominal inertia conditions (Fig 15],

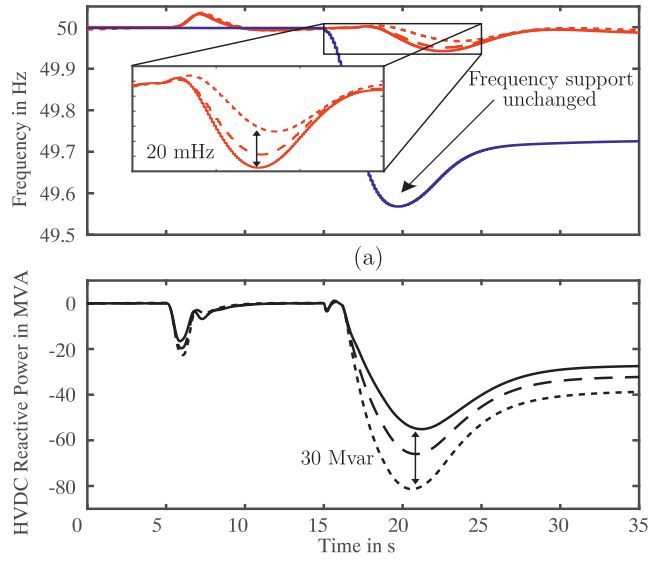

(b)

Fig. 13. Electrical distance variation between HVDC terminal and load: (a) System frequency in Area 1 (blue) and Area 2 (red), (b) HVDC reactive power variation with $0 \mathrm{~km}$ (solid), $25 \mathrm{~km}$ (dashed) and $50 \mathrm{~km}$ (dotted) transmission line

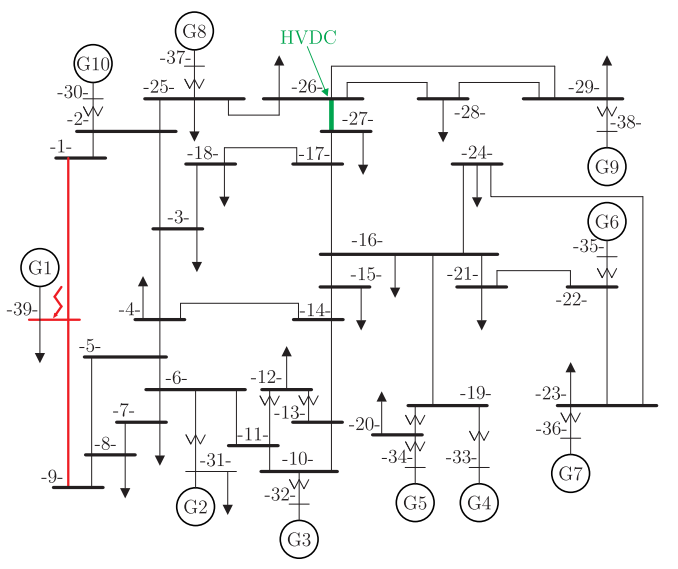

Fig. 14. Modified IEEE 39 bus system with HVDC system replacing the AC line between bus 27 (terminal 1) and 26 (terminal 2).

where the system is dominated by conventional generators and hence it has high aggregated inertia (i.e. $H=6 \mathrm{~s}$ ); and a case with lower inertia conditions (Fig 16), where the penetration of renewables (wind and PV) is higher and the equivalent inertia is reduced to $H=3 \mathrm{~s}$.

Due to the strong interconnected system, a change of the HVDC active power is ineffective to damp frequency oscillations. Consequently, only the effect of HVDC-based control of voltage dependent loads is analyzed in the following.

In the case of $H=6 \mathrm{~s}$ and no control of voltage dependent loads (indicated with no support in Fig 15 and Fig 16, the grid frequency increases up to $50.11 \mathrm{~Hz}$, due to the sudden active power mismatch (Fig 15 a)). If the control of voltage dependent loads is activated, the HVDC injects reactive power (Fig 15 b)) to vary the voltage at the loads PCC (Fig 15 c)).

Following the voltage variation, the active power consumption of the controlled load (Fig 15 (c)) increases and hence additional operation reserve for the frequency support is obtained. This reduces the frequency disturbance by $30 \mathrm{mHz}$, corresponding to a $30 \%$ frequency nadir improvement with respect to the case without PFR-VDL. As second effect, already described in the theory, the system damping increases, leading 

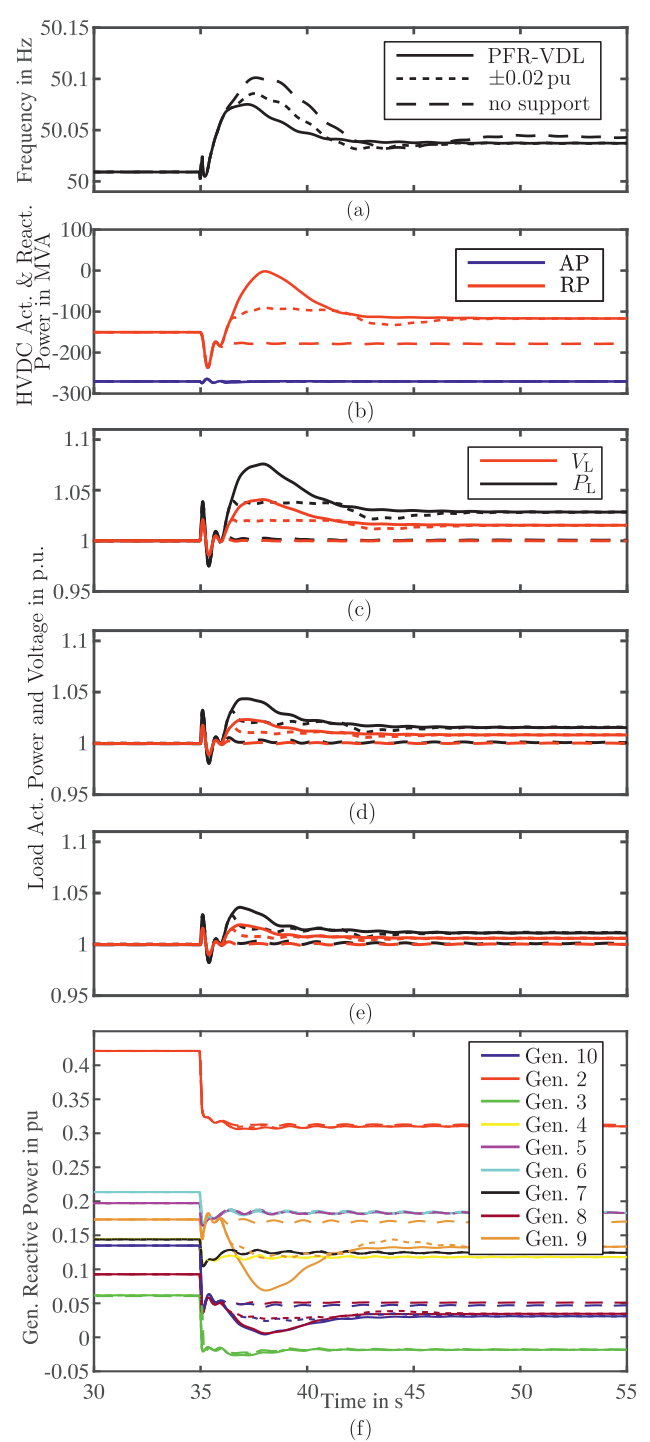

Fig. 15. Frequency event in IEEE 39-bus system in high inertia condition $(H=6 \mathrm{~s})$ w/o ('no support') and w/ PFR-VDL with $0.9-1.118 \mathrm{pu}$ ('PFRVDL') and \pm 0.02 pu voltage limitation (' $\pm 0.02 \mathrm{pu}$ '): (a) System frequency, (b) HVDC active and reactive power, Load active power and voltage: (c) bus 26, (d) bus 28 (e) bus 29, (f) generator reactive power.

to a reduced post-disturbance oscillation in the frequency (Fig 15 a)). The voltage is a local parameter, which can be influenced by the HVDC system through reactive power injection only at its PCC. Given the existence of several voltage dependent loads in the proximity of the HVDC terminal, not only a single particular load will be controlled, but other voltage dependent loads at connected buses ( 28 and 29, Fig 15 d) and Fig 15 (e)) will also partially reduce their consumption. However, the algorithm only requires soft load reduction and no firm load shedding and the participation of multiple voltage dependent loads is actually beneficial for frequency regulation. The PFR-VDL control is a short-term action used to stabilize the frequency in the first seconds after the disturbance. As soon as the frequency settles, the AVR of the generators restores the voltage by reactive power injection as depicted in Fig 15 (f). To be noted that the grid voltage controller in the terminal 2 of the HVDC system is always active. Since the grid voltage in
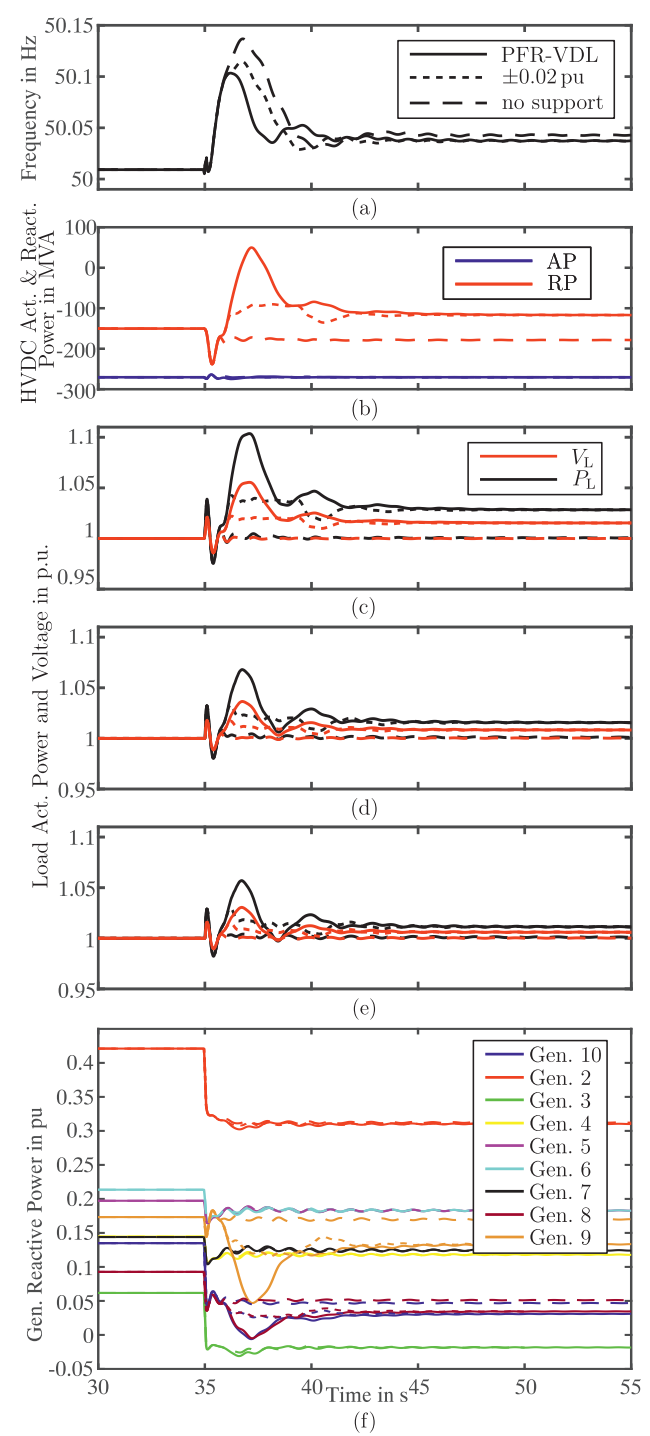

Fig. 16. Frequency event in IEEE 39-bus system in low inertia condition $(H=3 \mathrm{~s})$ w/o ('no support') and w/ PFR-VDL with $0.9-1.118 \mathrm{pu}$ ('PFRVDL') and $\pm 0.02 \mathrm{pu}$ voltage limitation (' $\pm 0.02 \mathrm{pu}$ '): (a) System frequency, (b) HVDC active and reactive power, Load active power and voltage: (c) bus 26, (d) bus 28, (e) bus 29, (f) generator reactive power.

the entire system experiences a sudden change following the frequency disturbance, the HVDC injects reactive power in the first seconds after the fault also in the absence of PFR-VDL action to support the grid voltage. Reduced system inertia leads to faster and larger frequency deviation after the disconnection of bus 39 (see Fig 16(a)). The HVDC applying the PFRVDL can reduce the frequency peak from original $50.14 \mathrm{~Hz}$ to $50.10 \mathrm{~Hz}$, corresponding to $\approx 30 \%$ reduction also in low inertia condition. However, this larger absolute compensation requires higher grid voltage variation (i.e. $5.5 \%$ in Fig 16 (c) compared to $4 \%$ in the high inertia case in Fig 15 (c)) and hence higher reactive power injection (i.e. plus 50 MVAr in Fig 16(b)).

\section{B. Evaluation of grid voltage constraints}

The current technical requirements for grid connection of HVDC systems constrain the maximum step-change in voltage 
through reactive power injection by $\pm 0.02 \mathrm{pu}$. The same two cases, conventional high inertia grid and renewable dominated low inertia grid, are repeated in Fig 15 and Fig 16 with dotted lines, respectively, limiting the voltage variation to $\pm 0.02 \mathrm{pu}$. As can be seen from Fig 15 and Fig[16 in both cases the frequency in the grid can still be supported, but with limited efficiency. If the inertia is high, the frequency oscillation reduction is $\approx 20 \mathrm{mHz}$ compared to $30 \mathrm{mHz}$ in the no-limited case, and if the inertia is low, $\approx 30 \mathrm{mHz}$ compared to $40 \mathrm{mHz}$. Since lower amount of reactive power is injected by the HVDC, the generators reactive power response is released.

\section{CONCLUSIONS}

HVDC can contribute to the primary frequency regulation varying the DC power flow proportionally with the frequency deviation. However, the fast control action impacts on the frequency in other DC-connected $\mathrm{AC}$ areas. This work proposed a HVDC-based primary frequency controller acting on voltage dependent loads as solution to overcome the classical controller limitations. The PFR-VDL enables additional upward and downward operational reserve by taking the energy required for supporting the frequency in a certain area (e.g., Area 1) not only from the generators but also from loads of another area (e.g., Area 2). Injecting reactive power, the HVDC shapes the power consumption of any voltage dependent load (HV substation, industrial aluminum or steel plant). As consequence, while the Area 1 frequency is adequately damped, the frequency oscillation in Area 2 is limited, compensating the local power imbalance. This work demonstrates the general control concept for HVDC systems in the two-area system proposed by [28], obtaining a reduction of second area frequency swing from $250 \mathrm{mHz}$ to $50 \mathrm{mHz}$, while effectively damping the frequency in the first area. The proposed PFR-VDL control is further validated in large interconnected IEEE 39 bus system, showing improvements in the frequency control, reducing the frequency nadir up to $30 \%$ with respect to the only droop controlled case, also in case of strict voltage constraints.

\section{REFERENCES}

[1] ENTSO-E, "Continental europe significant frequency deviations january 2019," January 2019.

[2] National Grid ESO, "Interim report into the low frequency demand disconnection (lfdd) following generator trips and frequency excursion on 9 aug 2019," August 2019.

[3] A. Ulbig, T. S. Borsche, and G. Andersson, "Impact of low rotational inertia on power system stability and operation," IFAC Proceedings Volumes, vol. 47, no. 3, pp. 7290 - 7297, 2014, 19th IFAC World Congress.

[4] A. Moglestue et al. (ABB Technology Ltd.), "Abb review, special report 60 years of hvdc," July 2014

[5] Y. Jiang-Haefner and P. Lundberg, "Vsc hvdc transmission support variable electricity generation," in 2016 CIGRE SESSION, 2016.

[6] M. Guan, J. Cheng, C. Wang, Q. Hao, W. Pan, J. Zhang, and X. Zheng, "The frequency regulation scheme of interconnected grids with vsc-hvdc links," IEEE Transactions on Power Systems, vol. 32, no. 2, pp. 864872, March 2017.

[7] N. R. Chaudhuri, R. Majumder, and B. Chaudhuri, "System frequency support through multi-terminal dc (mtdc) grids," IEEE Transactions on Power Systems, vol. 28, no. 1, pp. 347-356, Feb 2013.

[8] S. Akkari, J. Dai, M. Petit, and X. Guillaud, "Interaction between the voltage-droop and the frequency-droop control for multi-terminal hvdc systems," IET Generation, Transmission Distribution, vol. 10, no. 6, pp. 1345-1352, 2016.
[9] S. I. Nanou and S. A. Papathanassiou, "Frequency control of island vsc-hvdc links operating in parallel with ac interconnectors and onsite generation," IEEE Transactions on Power Delivery, vol. 33, no. 1, pp. 447-454, Feb 2018.

[10] M. Langwasser, G. D. Carne, M. Liserre, and M. Biskoping, "Frequency support provision by parallel, hybrid hvdc-hvac system with voltagebased load control," in 2019 IEEE Milano PowerTech, Oct. 2019.

[11] 50Hertz Transmission GmbH, Amprion GmbH, TenneT TSO GmbH, TransnetBW GmbH, "Netzentwicklungsplan Strom 2030, Version 2017. Zweiter Entwurf der Uebertragungsnetzbetreiber." 2017.

[12] "Load representation for dynamic performance analysis (of power systems)," IEEE Transactions on Power Systems, vol. 8, no. 2, pp. 472-482, May 1993.

[13] D. Chakravorty, B. Chaudhuri, and S. Y. R. Hui, "Estimation of aggregate reserve with point-of-load voltage control," IEEE Transactions on Smart Grid, vol. 9, no. 5, pp. 4649-4658, Sep. 2018.

[14] Y. Wan, M. A. A. Murad, M. Liu, and F. Milano, "Voltage frequency control using svc devices coupled with voltage dependent loads," IEEE Transactions on Power Systems, vol. 34, no. 2, pp. 1589-1597, March 2019.

[15] A. Moeini and I. Kamwa, "Analytical concepts for reactive power based primary frequency control in power systems," IEEE Transactions on Power Systems, vol. 31, no. 6, pp. 4217-4230, Nov 2016.

[16] G. De Carne, G. Buticchi, M. Liserre, and C. Vournas, "Real-time primary frequency regulation using load power control by smart transformers," IEEE Transactions on Smart Grid, pp. 1-1, 2018.

[17] Z. Wang and J. Wang, "Review on implementation and assessment of conservation voltage reduction," IEEE Transactions on Power Systems, vol. 29, no. 3, pp. 1306-1315, May 2014.

[18] M. Langwasser, G. D. Carne, M. Liserre, and M. Biskoping, "Voltagebased load control for frequency support provision by hvdc system," in IECON 2018 - 44th Annual Conference of the IEEE Industrial Electronics Society, Oct. 2018.

[19] T. H. Nguyen, K. A. Hosani, M. S. E. Moursi, and F. Blaabjerg, "An overview of modular multilevel converters in hvdc transmission systems with statcom operation during pole-to-pole dc short circuits," IEEE Transactions on Power Electronics, vol. 34, no. 5, pp. 4137-4160, May 2019.

[20] J. V. Milanovic, K. Yamashita, S. Martinez Villanueva, S. Z. Djokic, and L. M. Korunovic, "International industry practice on power system load modeling," IEEE Transactions on Power Systems, vol. 28, no. 3, pp. 3038-3046, Aug 2013.

[21] D. P. Stojanovic, L. M. Korunovic, and J. Milanovic, "Dynamic load modelling based on measurements in medium voltage distribution network," Electric Power Systems Research, vol. 78, no. 2, pp. 228 - 238, 2008.

[22] G. Delille, L. Capely, D. Souque, and C. Ferrouillat, "Experimental validation of a novel approach to stabilize power system frequency by taking advantage of load voltage sensitivity," in 2015 IEEE Eindhoven PowerTech, June 2015, pp. 1-6.

[23] D. S. Callaway and I. A. Hiskens, "Achieving controllability of electric loads," Proceedings of the IEEE, vol. 99, no. 1, pp. 184-199, Jan 2011.

[24] G. De Carne, M. Liserre, and C. Vournas, "On-line load sensitivity identification in lv distribution grids," IEEE Transactions on Power Systems, vol. 32, no. 2, pp. 1570-1571, March 2017.

[25] A. Ballanti, L. N. Ochoa, K. Bailey, and S. Cox, "Unlocking new sources of flexibility: Class: The world's largest voltage-led load-management project," IEEE Power and Energy Magazine, vol. 15, no. 3, pp. 52-63, May 2017.

[26] ENTSO-E, "Network code on operation security," February 2013

[27] VDE, "Vde-ar-n 4131 technical requirements for grid connection of high voltage direct current systems and direct current-connected power park modules (tar hvdc)," Mar. 2019, german Language Version.

[28] P. Kundur, Power System Stability and Control. Electric Power Research Institute, 1994.

[29] G. De Carne et al., "Which deepness class is suited for modeling power electronics?: A guide for choosing the right model for grid-integration studies," IEEE Industrial Electronics Magazine, vol. 13, no. 2, pp. 4155, June 2019.

[30] K. Strunz et al., "Benchmark systems for network integration of renewable and distributed energy resources," WG C6.04, Task Force C6.04.02 Technical Brochure 575, 2014.

[31] K. R. Padiyar, "Energy function analysis for power system stability," Electric Machines \& Power Systems, vol. 18, no. 2, pp. 209-210, 1990. 


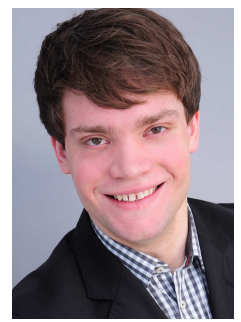

Marius Langwasser (S'16) received the B.Sc. and M.Sc. degree in electrical engineering and business administration at Kiel University, Kiel (Germany) in 2014 and 2016, respectively. Since 2016 he is scientific staff member and $\mathrm{PhD}$ student at the Chair of Power Electronics at Kiel University. His research interests include control and protection of multiterminal DC grids and ancillary service provision with HVDC.

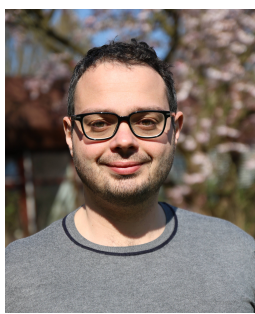

Giovanni De Carne (S'14-M'17) received the M.Sc. in Electrical Engineering from Polytechnic University of Bari, Bari (Italy) in 2013. Since 2013, he carried out his Ph.D. studies at the Chair of Power Electronics at Kiel University, Germany. He defended his doctoral thesis in 2018, and continued working at Kiel university as post-doc on HVDC control and services until 2019. He is currently the Team Leader of the "Real Time System Integration" group at the Institute for Technical Physics at the Karlsruhe Institute of Technology, working on largescale power hardware in loop systems and hybrid networks. He is associate editor of the IEEE "Industrial Electronics Magazine" and Springer Journal "Electrical Engineering". He is author and co-author of more than 50 technical papers, and he is member of PELS, IES and PES, where is an active author and reviewer of journals and conferences of these societies.

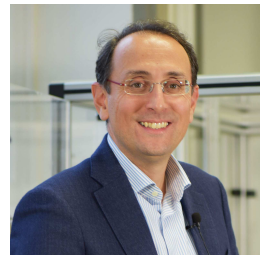

Marco Liserre (S'00-M'02-SM'07-F'13) received the M.Sc. and $\mathrm{PhD}$ degree in Electrical Engineering from the Bari Polytechnic, respectively in 1998 and 2002. He has been Associate Professor at Bari Polytechnic and from 2012 Professor in reliable power electronics at Aalborg University (Denmark). From 2013 he is Full Professor and he holds the Chair of Power Electronics at Kiel University (Germany). He has published 500 technical papers $(1 / 3$ of them in international peer-reviewed journals) and a book. These works have received more than 33000 citations. Marco Liserre is listed in ISI Thomson report "The world's most influential scientific minds" from 2014. He has been awarded with an ERC Consolidator Grant for the project "The Highly Efficient And Reliable smart Transformer (HEART), a new Heart for the Electric Distribution System". He is member of IAS, PELS, PES and IES. He has been serving all these societies in different capacities. He has received the IES 2009 Early Career Award, the IES 2011 Anthony J. Hornfeck Service Award, the 2014 Dr. Bimal Bose Energy Systems Award, the 2011 Industrial Electronics Magazine best paper award and the Third Prize paper award by the Industrial Power Converter Committee at ECCE 2012, 2012, 2017 IEEE PELS Sustainable Energy Systems Technical Achievement Award and the 2018 IEEE-IES Mittelmann Achievement Award.

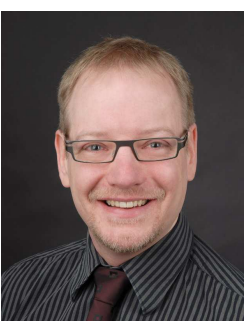

Matthias Biskoping received the Ph.D degree in electrical engineering from RWTH Aachen University, Germany, in 2019. From 2010 to 2015, he was with the Institute for Power Electronics and Electrical Drives (ISEA), RWTH Aachen University, as a Research Associate and a Group Leader for power electronics. In 2016, he started working as a Senior Scientist at the German Corporate Research Center of ABB AG, Ladenburg, Germany and since 2020 he is heading a group for "Optimization and Control" at the research center of ABB AG. His research interests include the modeling and optimization of energy systems, control of power electronic converters and e-mobility. 